\title{
Cipango
}

Cipango Cahiers d'études japonaises

$20 \mid 2013$

Nouveaux regards sur les arts de la scène japonais I

\section{Écrits sur le théâtre : Higashi Yutaka et Yū Miri}

\section{Toshio Takemoto}

\section{(2) OpenEdition}

\section{Journals}

\section{Édition électronique}

URL : https://journals.openedition.org/cipango/1967

DOI : $10.4000 /$ cipango. 1967

ISSN : 2260-7706

\section{Éditeur}

INALCO

\section{Édition imprimée}

Date de publication : 30 octobre 2013

ISSN : 1164-5857

\section{Référence électronique}

Toshio Takemoto, «Écrits sur le théâtre : Higashi Yutaka et Yū Miri », Cipango [En ligne], 20 | 2013, mis en ligne le 17 avril 2015, consulté le 30 juin 2021. URL : http://journals.openedition.org/cipango/1967 ; DOI : https://doi.org/10.4000/cipango.1967

Ce document a été généré automatiquement le 30 juin 2021.

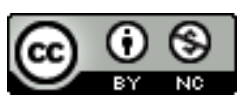

Cipango est mis à disposition selon les termes de la Licence Creative Commons Attribution - Pas d'Utilisation Commerciale 4.0 International. 


\title{
Écrits sur le théâtre : Higashi Yutaka et Yū Miri
}

\author{
Toshio Takemoto
}

Higashi Yutaka 東由多加 (1945-2000) et Yū Miri 柳美里 (1968-) sont des figures incontournables du théâtre contemporain japonais entre les années 1960 et les années 1990, bien que leurs créations théâtrales, méconnues à l'étranger, commencent à être oubliées au Japon même. Aujourd'hui, Yū Miri est reconnue essentiellement comme auteure de romans autofictionnels; peu de critiques mentionnent encore ses travaux théâtraux, à l'exception de Lisa Yoneyama ${ }^{1}$. Pourtant son expérience du théâtre nous semble essentielle pour comprendre son esthétique. Ainsi, si « son œuvre tout entière est exhibition de ses tourments existentiels, mettant en scène l'impossible intégration face au poids de l'histoire ${ }^{2}$ ", n'est-ce pas précisément parce que Yū a commencé sa carrière à l'âge de quinze ans en tant que stagiaire de la compagnie théâtrale Tōkyō Kid Brothers, dirigée par le dramaturge et metteur en scène Higashi Yutaka $^{3}$ ? Celui-ci, en effet, et Yû le raconte dans l'éloge funèbre traduit à la fin de ce dossier, travaillait, sans doute sous l'influence de Kishida shū 岸田秀 (1933-), psychiatre freudien dont Higashi fut le lecteur, comme un thérapeute qui remue le passé traumatique du patient afin que celui-ci verbalise des souvenirs oubliés. En tant que metteur en scène, il cherchait à faire resurgir le moi profond du comédien, en déterrant ses souvenirs enfouis. Lorsque Yū décrira minutieusement, une quinzaine d'années après ses débuts, son expérience au sein de la troupe, elle rapportera presque mot pour mot les leçons de son maître ${ }^{4}$. Proposer des traductions parallèles des essais de ces deux auteurs nous semble ainsi particulièrement opportun pour donner un aperçu - certes trop rapide - de leur esthétique théâtrale respective.

\section{Higashi Yutaka}

2 Né en 1945 à Taiwan, Higashi monte à Tōkyō en 1967. Inscrit à l'université Waseda, il s'enthousiasme pour le théâtre dont cette université est un haut lieu, rencontre Terayama Shūji 寺山修司 (1935-1983), poète et homme de théâtre talentueux. Ils 
fondent ensemble la compagnie de théâtre « underground » $»^{5}$ Tenjōsajiki 天井栈敷 (Les enfants du Paradis) le premier janvier 1967. Désireux toutefois de créer une œuvre représentative de sa propre génération, le jeune metteur en scène quitte Terayama à l'âge de vingt-trois ans et fonde, en 1968, la « Tōkyō Kid Brothers Company » (Tōkyō kiddo kyōdai shōkai 東京キッド兄弟商会), avec laquelle il monte dans un café de Shinjuku son premier spectacle, "La huitième symphonie restait inachevée " (Kōkyōkyoku daihachiban wa mikansei datta 交響曲第八番は未完成だった) : le café ne désemplit pas jusqu'à la dernière représentation ${ }^{6}$. En 1970, il remporte un succès fulgurant à New York avec Golden Bat, où il met en scène de jeunes Japonais aspirant à la liberté américaine et déçus par la réalité du pays enlisé dans la Guerre du Viêt Nam7.

3 Parallèlement à son activité théâtrale, Higashi entreprend, en 1971, de réaliser un rêve de vie égalitaire et communautaire en toute liberté dans un village abandonné de l'archipel, Sajimura 佐治村, dans le département de Tottori. Là, il tente de construire une communauté avec des lycéens, des étudiants et des ouvriers, etc. Son projet, baptisé «l'Utopie des cerises» (Sakuranbo yūtopia さくらんぼユートピア), sera un échec cuisant. Il revient alors au théâtre et ouvre le Theater 365 en 1977 dans une petite salle souterraine de Shinjuku. Il y monte des spectacles originaux pendant un an. C'est le deuxième âge d'or de la Tōkyō Kid Brothers. Son manifeste théâtral « Amour et Solidarité » (Ai to rentai 愛と連帯) ${ }^{8}$ est chargé d'un espoir teinté d'amertume : malgré l'échec de l'Utopie du cerisier, il ne cesse d'aspirer à une vie communautaire dans une Cité idéale dont les membres sont unis par l'amour. Entre 1968 et 1990, il écrit environ quatre-vingt-dix comédies musicales ${ }^{9}$.

4 Nous présentons ci-dessous en version intégrale quelques-uns de ses essais écrits entre 1971 et 1976. Ceux-ci tracent à la fois l'autoportrait d'un jeune dramaturge et un témoignage sur une époque où l'on passait progressivement d'un engagement social enthousiaste à un désengagement - ou plutôt à un rêve de vie égotiste au Japon.

5 «Départ pour la pérégrination vers l'Ouest 》(Saiyūki e no shuppatsu 西遊記への出発) ${ }^{10}$ se situe dans une période transitoire entre le succès remporté par la comédie musicale Golden Bat et le fiasco de «l'Utopie des cerises ». Le jeune Higashi, avec tout l'optimisme de ses vingt-six ans, ne se contente pas de rechercher une évasion dans la fiction théâtrale. Il s'oppose à la société japonaise en plein essor économique, qui contrecarre la liberté de l'individu. D'autre part, son esthétique se fonde sur un sentimentalisme auquel il tient fermement. Pour lui, le théâtre est avant tout une fête célébrée en dehors de l'ordre social établi.

6 Publiés respectivement en 1975 et en 1976, les essais "Tout le monde, en son passé révolu...» (Hito wa daremo sugisatta kako ni... 人は誰も過ぎ去った過去に...) et 《la Dérive est la nourriture de notre vie» (Hōrō wa oretachi no inochi no kate 放浪は俺たち の命の糧) forment un diptyque. Écrit en 1975 pour le livret du spectacle «Octobre, patrie de pénombre " (Jūgatsu wa tasogare no kuni 十月は黄昏の国), le premier essai dessine le visage d'un homme de trente ans qui conserve toute la ferveur du soixantehuitard, et qui ressent un attachement profond pour Akita Meidai 秋田明大 (1947-), personnage qui dirigea l' "Union des étudiants combattants de l'université Nihon " (Nichidai Zenkyōtōo日大全共閂: près de cent mille étudiants en lutte contre les autorités en 1968). Mais, au milieu des années 1970, les jeunes gens croient de moins en moins à l'idéal communautaire. De cet essai se dégagent autant une remise en question du rêve utopisant de Higashi qu'un encouragement à son public : il faut continuer à vivre avec passion afin de continuer à lutter pour l'amour. Son théâtre en est l'exemple. 
Le deuxième essai est publié dans le magazine Playboy. Higashi choisit pour ses jeunes lecteurs une anecdote personnelle qui révèle avec humour l'idée qu'il se fait du voyage : il les incite à vivre pleinement l'amour et à se perdre dans la vie, précisément parce que rien n'est sûr. On voit à travers ses lignes une tranche de vie que lui-même a menée avec les Tōkyō Kid Brothers aux États-Unis, puis en Europe et au Japon, au début des années 1970.

\section{Yū Miri}

7 Yū Miri est née en 1968 de parents coréens, qui s'installent à grand-peine au Japon avant de se séparer. Son enfance et son adolescence sont marquées par les violences que lui inflige son géniteur et par son exclusion du milieu scolaire nippon ${ }^{11}$. Ses œuvres offriront de fait l'image de familles brisées qui renvoient tant à la difficulté d'être une fille qu'à l'aspiration à l'unité familiale. Cette ambivalence - on l'a assez dit - est au cœur de sa littérature. Après son travail avec les Tōkyō Kid Brothers, elle fonde en 1988 sa propre troupe, le « Parti de Mai de la Jeunesse » (青春五月党 Seishun Gogatsu-tō), et écrit dix pièces - inédits compris - qui illustrent dans une tonalité autofictionnelle ses thèmes récurrents : le suicide, les interrogations identitaires, la famille ${ }^{12}$. À vingt-trois ans, elle obtient le prestigieux prix de théâtre Kishida Kunio (岸田国士戯曲賞 Kishida Kunio Gikyoku-shō) pour «Le festival des poissons»(Uo no matsuri 魚の祭り). Pourtant, dès le milieu des années 1990, elle s'oriente vers l'écriture romanesque. Il faut néanmoins souligner que l'expérience théâtrale reste indissociable de sa création, comme le précise la critique allemande Kristina Weickgenannt ${ }^{13}$. Si Weickgenannt s'intéresse par ailleurs aux récentes apparitions médiatiques de l'auteure dans des émissions télévisées et sur son propre blog ${ }^{14}$, les essais traduits ici montrent déjà des éléments d'auto-mise en scène. Yū tente de fabriquer sa propre image en écrivant des tranches de vie, ou plutôt des chapitres de son récit de vie. Outre son esthétique théâtrale, ces essais retracent son parcours créatif et son propre cheminement. Mieux : ils témoignent de sa création en tant qu'auteure de son propre univers littéraire, du théâtre au roman.

Avec « la Nuit dans la nuit» (Yoru no naka no yoru 夜の中の夜), parue dans Théatro (テ アトロ Teatoro) en février 1993, Yū passe de l'autoportrait de la jeune femme agacée qu'elle est à la description métaphorique de l'espace théâtral ténébreux où gît le secret des hommes. Trop rhétorique peut-être, l'écriture est déroutante: hyperbole, gradation, effets de contraste, style poétique. Mais n'est-ce pas un dispositif efficace pour placer soudain le lecteur dans cet espace déconcertant qu'est le théâtre?

Publié dans le quotidien Kōmei shinbun 公明新聞 le 7 avril 1994, «l'Art théâtral de l'école 'décadente'》 ('Buraiha' engekijutsu 《無頼派》演劇術) révèle avec humour son admiration pour l'écrivain Dazai Osamu 太宰治 (1909-1948) et le poète Nakahara Chūya 中原中也 (1907-1937). La jeune dramaturge explique se donner pour but de mettre en scène un désir irréalisable dans la vie quotidienne, d'où son ambition démesurée d'en finir avec son passé familial pour configurer à l'infini les images de famille. Autant dire que sa création n'est pas réductible à la reproduction de son propre vécu.

10 Signé en 1994 pour le journal Tōkyō shinbun 東京新聞, « Un drame inachevé » (Mikan no dorama 未完のドラマ) est l'acte de naissance de la romancière Yū Miri. Si elle écrivait ses pièces pour manifester sa haine pour le monde, la création romanesque devrait elle lui permettre de surmonter son passé familial douloureux. Mais il lui faudra attendre 
au moins dix ans pour y parvenir, tout en fabriquant des personnages incarnant une réconciliation possible entre la Corée et le Japon ${ }^{15}$, puis entre le présent et le passé ${ }^{16}$.

11 《Déploration pour la mort de Higashi Yutaka » (Higashi Yutaka wo itamu 東由多加を悼 む) atteste de la maturité de Yū, romancière confirmée en 2000. Le présent de la narration encadre leurs passés où se mêlent leurs liaisons passionnelles et artistiques. L'écriture est sobre, alors qu'elle vient de perdre l'homme qui était pour elle le plus proche. Le lecteur, lui, a le sentiment d'être présent à la cérémonie funéraire quand elle relate le souvenir des Tōkyō Kid Brothers. Ce texte fut diffusé quinze jours après le décès de Higashi par l'agence de presse Kyōdō tsūshin 共同通信. Yũ achève son livre «Le rêve du poisson » par ce discours funèbre en hommage à l'homme de théâtre ${ }^{17}$.

Enfin, pour clore cette présentation, quelques éléments bibliographiques : les essais de Higashi sont tirés de Higashi Yutaka ga nokoshita kotoba (Mots légués par Higashi Yutaka), œuvre posthume éditée chez Jiritsu shobō (maison d'édition spécialisée dans les ouvrages théâtraux) par Hisau Jikko 久生実子, membre de la production des Tōkyō Kid Brothers. Les essais de Yū sont quant à eux extraits de Sakana ga mita yume (Le rêve du poisson), tome regroupant des textes écrits entre vingt-trois ans et trente-deux ans soit durant les années qui marquèrent son passage du statut de dramaturge à celui de romancière ${ }^{18}$. Dans ce livre apparaît en filigrane un personnage appelé le «metteur en scène » : n'est-ce pas un signe de la connivence entre Yū et Higashi ? ${ }^{19}$

\section{NOTES}

1. Lisa YONEYAMA, "Reading Against the Bourgeois and National Bodies: Transcultural BodyPolitics in Yu Miri's Textual Representations", in Koreans in Japan. Critical Voices from the Margin, Sonia RYANG (éd.), 2006 (2000), pp. 105-106.

2. Cécile SAKAI à propos de Hachigatsu no hate 8 月の果て, (À la fin du mois d'août), roman polyphonique paru en 2004 ; «Exil versus mondialisation », in Chantal CHEN-ANDRO, Cécile SAKAI et Xu SHUANG (dir.), Imaginaires de l'exil dans les littératures contemporaines de Chine et du Japon, Arles, Philippe Picquier, 2012, p. 276.

3. Voir KUME Yoriko 久米依子, “Dangai no ue kara hakobune e » 断崖の上から方舟へ (Du précipice à l'arche), in HARA Hitoshi 原仁司 (dir.), Yū Miri 1991-2010 柳美里 $1991-2010$, Tōkyō, Kanrin shobō 翰林書房, 2011, p. 41-59.

4. Voir le dernier chapitre de son roman autofictionnel Mizube no yurikago 水辺のゆりかご (le Berceau au bord de l'eau). YŪ Miri, Tōkyō, Kadokawa shoten 角川書店, 1999 (1997), p. 201-269.

5. Angura アングラ, théâtre avant-garde ou expérimental, très actif dans les années 1960.

6. HIGASHI Yutaka, Chikyū yo tomare, boku wa hanashitainda 地球よとまれ、僕は話したいんだ

(Terre, arrête de tourner ! J'ai envie de parler), Tōkyō, Kōdansha 講談社, 1981, p. 22.

7. Ibid., p. 28-42.

8. HIGASHI Yutaka, Higashi Yutaka ga nokoshita kotoba 東由多加が遺した言葉 (Mots légués par Higashi Yutaka), Tōkyō, 而立書房 Jiritsu shobō, 2002, 222 p., ici p. 73.

9. Ibid., p. 195-200. Voir aussi le site de fans «Endless $\infty$ Kidbros » : http://www.endless-kid.net (consulté le 28 juin 2012). 
10. On ignore à quelle occasion et pour quel magazine cet essai fut rédigé. La Pérégrination vers l'Ouest (Saiyūki en japonais) est un célèbre roman chinois de la fin du Xvi ${ }^{\mathrm{e}}$ siècle (Wu Cheng'en, la Pérégrination vers l'Ouest [Xiyou ji], trad. française André Lévy, Paris, Gallimard, La pléiade, deux vol., 1991). Higashi se sert de cette référence pour ouvrir l'horizon d'attente du lecteur et préparer son éloge du vagabondage.

11. Kristina WEICKGENANNT, "The De-emphasis of Ethnicity: Images of Koreanness in the Works of the Japanese-Korean Author Yū Miri", Electronic Journal of Contemporary Japanese Studies, Conference and Seminar Papers, "Images of Asia in Japanese Mass Media, Popular Culture and Literature", presented at ICAS 2, Berlin, August 2001 : http://www.japanesestudies.org.uk/ejcjs/ authors/index.html - W, p. 3 (consulté le 23 juin 2012). Voir également Cécile SAKAI, op. cit., et YoSHIDA Aki «Exil forcé, exil choisi : les œuvres en langue japonaises des auteurs coréens ", in Imaginaires de l'exil..., op. cit., p. 244-246.

12. YŪ Miri, Now and then - Yū Miri jishin ni yoru zensakuhin kaisetsu to +51 no shitsumon, Now and then 柳美里による全作品解説＋51 の質問 (Maintenant et jadis, autocommentaire des œuvres par Yū Miri elle-même + 51 questions), Tōkyō, Kadokawa shoten 角川書店, 1997, p. 44-53.

13. «Cette rencontre [avec le théâtre] a marqué un tournant dans la vie de Yū »; WEICKGENANNT, op. cit., p. 3.

14. Ce que Weickgenannt appelle des performative elements. Citée par Matthew KöNIGSBERG dans le compte-rendu qu'il fait de son livre Alles nur Theater? Gender und Ethnizität bei der japankoreanischen Autorin Yu Miri (Munich, Iudicium, 2008) dans Monumenta Nipponica, 64 : 1, 2009, p. 224 ; i.dijtokyo.org/reviews/rez_alltheater_\%20mn.pdf(consulté le 23 juin 2012).

15. Hachigatsu no hate 8月の果て (À la fin du mois d'août), Tōkyō, Shinchōsha 新潮社, 2004, $832+2 \mathrm{p}$.

16. Ame to yume no ato $n i$ 雨と夢のあとに (Après la pluie et le rêve), Tōkyō, Kadokawa shoten, $2005,283+4 \mathrm{p}$.

17. Yū Miri, Sakana ga mita yume 魚が見た夢 (le Rêve du poisson), (2000)2003, Shinchōsha, 333 p.

18. Publié en 2000 par la grande maison d'édition Shinchōsha, ce livre fut intégré en collection de poche trois ans plus tard, témoignant de la popularité de l'auteure.

19. Dans les traductions qui suivent, toutes les notes sont du traducteur.

\section{AUTEUR}

\section{TOSHIO TAKEMOTO}

Université de Lille 3, INALCO-CEJ 